\title{
Clumped Isotopes All Grown Up: How the Use of Carbonate Reference Materials Solves Long-Standing Issues of $\Delta 47$ Standardization and Calibration
}

\author{
STEFANO M. BERNASCONI ${ }^{1}$, MATHIEU DAËRON ${ }^{2}$, \\ KRISTIN BERGMANN ${ }^{3}$, MAGALI BONIFACIE ${ }^{4}$ AND \\ ANNA NELE MECKLER ${ }^{5}$
}

${ }^{1}$ ETH Zürich

${ }^{2} \mathrm{CNRS} / \mathrm{LSCE}$

${ }^{3}$ Massachusetts Institute of Technology

${ }^{4}$ IPGP/CNRS UMR 7154

${ }^{5}$ University of Bergen

Presenting Author: stefano.bernasconi@erdw.ethz.ch

Since its establishment fifteen years ago at Caltech, carbonate clumped isotope thermometry has grown to the be most widely applied branch of the rapidly evolving field of clumped isotope geochemistry. An increasing number of laboratories worldwide is implementing this technique and applying it to solve a broad range of Earth science questions. The lack of recognized international standards, inter-laboratory differences in analytical methods and data processing however, however, has so far limited the confidence in temperature reconstructions based on this method especially in research aiming to resolve small temperature differences for climate reconstructions. A recent community effort to solve interlaboratory discrepancies involving 22 laboratories, the InterCarb interlaboratory calibration exercise (Bernasconi et al. 2021), has demonstrated that using carbonate standards and consistent data normalization procedures (Daëron, 2021), yields inter-laboratory discrepancies entirely consistent with intra-laboratory analytical uncertainties. In addition, a recent reanalysis of samples from previous calibrations (Anderson et al. 2021) with a consistent carbonate standardization scheme, shows that discrepancies in published calibrations also probably reflect differences in analytical methods rather than true differences in temperature dependence of different minerals. In this contribution we will review the state of the art in standardization and laboratory protocols and discuss future steps to provide the carbonate clumped isotope community with a robust approach to achieve better inter-laboratory agreement as we continue to use and improve this powerful geochemical tool.

References:

Anderson et al., (2021) A unified clumped isotope thermometer calibration $\left(0.5-1100^{\circ} \mathrm{C}\right)$ using carbonatebasedstandardization. Geophysical Research Letters. In press

Bernasconi et al., (2021) InterCarb: A community effort to improve inter-laboratory standardization of the carbonate clumped isotope thermometer using carbonate standards. Geochemistry, Geophysics, Geosystems. In press

Daëron (2021), Full propagation of analytical uncertainties in $\Delta_{47}$ measurements. Geochemistry, Geophysics, Geosystems. In press 